\title{
Thinking Of Multimedia Courseware And Teaching Innovation On Vocational Colleges
}

\author{
Wei Zhang \\ Shenzhen Polytechnic Guangdong 518008, PR China \\ 1215556531@qq.com
}

Keywords:Multimedia teaching courseware, the teaching innovation

\begin{abstract}
Multimedia teaching has the characteristics of interest, mainly through the text, graphics, images, animation, sound, video and interactive network to the students' sense to form a variety of stimulation, make the teaching content, lively stimulate students' learning enthusiasm, effectively break through the emphases and difficulties in the teaching, improve the learning efficiency.
\end{abstract}

\section{Introduction}

The introduction of multimedia teaching means in teaching process with multimedia computer as the core of modern teaching tool and means of a new type of teaching mode. It created a new field of interest teaching, mainly through the text, graphics, images, animation, sound, video and interactive network and so on, to the students' sense to form a variety of stimulation, make the teaching content, lively stimulate students' learning enthusiasm, effectively break through the emphases and difficulties in the teaching, improve the learning efficiency. At present our country in the vocational school in the making and using of multimedia courseware, there are still many problems worthy to be discussed, especially in general lack of innovation during the courseware making. This article carries on the discussion to this, more education workers focus on the use of multimedia teaching in the vocational teaching, in order to make the modern teaching means can play its due role in China's vocational education.

\section{Multimedia learning cognitive theory and cognitive model}

Multimedia learning cognitive theory is a contemporary American education psychologists, a cognitive psychologist Richard e. meyer in his book "the multimedia learning" is put forward, and through a lot of psychological experiments prove the validity and scientific theory. Mayer thinks "according to the person's psychology works design of multimedia information than no way according to the person's psychology working design of multimedia information is more likely to have a meaningful learning", based on this understanding, meyer multimedia learning cognitive regularity is studied, based on the dual channel hypothesis, hypothesis assume limited capacity, actively processing the psychology principle of multimedia cognitive model is established. Multimedia learning cognitive theory of the three hypotheses:

1. dual channel assumption. Refers to people in the cognitive process of visual representation and auditory characterization of materials has a corresponding information processing channel.

2. limited capacity hypothesis. People during cognitive processing is the need to consume the cognitive resources, and cognitive resources is limited, so in each channel last machining information quantity is also limited.

3. actively processing hypothesis. Refers to the people in order to present the material in accordance with their experience to build the mental representation will actively participate in cognitive processing. Active cognitive process including attention, information and the new new entrants to the organization of information integration and other knowledge.

Multimedia learning cognitive model also represents information processing system, the model of image reflects the learning principle of multimedia learning human; In words and pictures to present the multimedia materials, respectively through the auditory channel and the visual channel into the person's feeling memory center, to point out is the text of the words material, is by the eyes feeling 
through visual path to the memory center, into sensory memory center of vision and hearing representation can briefly, then need to choose, the choice of visual and auditory representation is based on the hypothesis, limited capacity in the corresponding channel in the center of the sensory memory can choose only limited information into the working memory center. Multimedia learning occurs in the work, and the main process, under the active state of consciousness, working memory used to temporarily store knowledge and operation processing knowledge, working memory is based on dual channel, thus at the completion of the corresponding channel of information model in the information construction, also need to establish connections between two kinds of channels, the appearance is associated with the auditory and visual imagery, the need to extract the previous knowledge in the long-term memory, will be processed after integrating information and prior knowledge, and stored into long-term memory.

\section{The understanding deviation of multimedia courseware and use}

From the current vocational school in our country the construction of multimedia classrooms and multimedia courseware (network) make use of current situation, many schools on the understanding of multimedia teaching still exist some fuzzy concept, has the following several aspects of understanding deviation.

The use of multimedia teaching is the teaching modernization Now many vocational school attaches great importance to apply multimedia teaching, then not hesitate heavy gold, investment for the construction of the multimedia classroom, set up schools within the domain network, encourage teachers to make multimedia courseware. Even the administrative department of education in China is a school with the number of number of computers, multimedia classroom as an important indicator of school level.Using multimedia teaching is one of the modernization of teaching means, but not all of the modernization of teaching. Even with a large number of multimedia classroom, even if all the courses are using multimedia teaching, also is not equal to realize the modernization of teaching. The modernization of teaching implementation, in addition to the necessary conditions and modern facilities, more important is the teaching ideas and teaching knowledge and modern teaching methods. Just think, if teachers just put the content of the teaching material to make multimedia courseware, and then play in class, what is the difference between it and the traditional teaching?

The production of multimedia courseware is "clone" teaching material For our country's at present vocational school teachers, academic teachers and the professional class to the operation of the use of multimedia software to make teaching courseware technology is not very familiar with. So difficult, making multimedia courseware must be with the aid of computer professional teacher's help and cooperation. But the computer professional teachers are not necessarily familiar with the content of other specialized courses. So, some of the multimedia courseware is the teaching material content "clone", only the copy of teaching content, some even its effect also is inferior to the teaching material content integrity.

Any course content can use multimedia teaching There is no doubt that proper use of multimedia teaching, really to have dictation of the traditional hand can't reach the effect of teaching. For example, multimedia teaching intuitive vivid, the characteristics of static to dynamic, to extend classroom boundaries of time and space, and can be a lot of students of the initiative of the senses such as vision, hearing and touch, resulting in a strong artistic appeal, and so on. Practice has proved, however, not all of the course is made after the use of multimedia courseware teaching can achieve the effect. Some application of multimedia in the teaching material content is suitable for teaching, and some are not suitable for multimedia teaching. Like computer class curriculum, if the teachers also make the teaching content into multimedia courseware, the courseware itself is not beyond the original content, wouldn't it be redundant. So, the idea that any course can use the concept of the multimedia courseware to show obviously there's a certain one-sidedness.

Using the multimedia teaching can improve teaching quality Using multimedia teaching can improve teaching quality in a certain sense. Multimedia teaching, which can solve problems cannot be solved in traditional teaching, simplify some complex problems or visualization, easy to accept students. But the multimedia teaching is just an auxiliary means of teaching, only suitable for some of 
the course content. At present, almost impossible to all the content is a course to make multimedia courseware. Therefore, the improvement of teaching quality whether or not can't depend on using the multimedia teaching means in teaching, at least it won't be decisive role. In general too much use of multimedia courseware in teaching, especially those in production and no new idea, boring, just "clone" textbook content of the multimedia courseware, causes student's disgust, thus reducing the study appeal, let alone is beneficial to improve the teaching quality.

\section{The principle of multimedia courseware design and making}

Multimedia cognitive principles Multimedia courseware in words and pictures will be better than only words to present the learning effect is good, simple speaking is required in the network course is best graphic combination, in particular to describe the complex relationships or something complex principle, when the words and pictures to present, learners will reduce cognitive resources consumption, the study compared the mental models of language and image and establish contact between them.

Close to the principle of space and time Multimedia courseware are associated with words and images should be close to in space and time; Specifically space is close to the text of the related illustrations can not be too far away from the, should be displayed on a screen can, close to the time is required in the corresponding words and pictures to present at the same time, for example in the sound and picture shows something, the corresponding picture and need to present at the same time; Space-time close to make learners are more likely to be in verbal representation and visual representation is maintained between the two materials of mental representation, leading to the possibility of establish psychological contact between representation and visual representation in words; If not present at the same time, learners need to consume the corresponding cognitive resources to form the relationship between words and visual property. Therefore, the multimedia courseware of multimedia information on the location and time as far as possible close to is necessary; Will be related with the figure of the text, for example, integrated into the figure, the related content as far as possible with a screen display, synchronize the sound painting, using synchronous communication, etc.

Principle of channel Multimedia learning cognitive theory points out that composed of animation and rendering than composed of animation and screen text rendering can make learners learn better, that is to say, in the multimedia courseware, and the image of the words in the form of sound more can promote learners' learning than in the form of text, images and words this is because when materials are based on visual form, will increase the cognitive load of visual channel, and the cognitive load of auditory channel in the idle state, can not effectively use cognitive resources; When present in the form of sound words material, people can in the visual image information processing, as well as in auditory channel talked information processing, the use of cognitive resources as far as possible. At present a lot of multimedia courseware is a simple video, based on the principle of channel, in this interpretation claim form with the sound of multimedia courseware, rather than in the form of text interpretation.

Principle of redundancy This redundancy refers to the redundancy of information, multimedia learning cognitive theory, points out that learners learning consists of animation and explanation of present material than learning of animation and explanation plus screen text rendering material to achieve better effect, the explanation and screen text shows the words of the same information; Of course, there are news dissemination theory subtitles reconciliation is complementary to each other, people can not only see the subtitles when you watch the video and can listen to, and when there is pronunciation explanation, the problem such as talking too fast and watch learning effects, and can be gained by watching subtitles clear explanation; In principle but multimedia learning cognitive theory explains the human learning process of multimedia material, dual channel assumption and limited capacity hypothesis can explain scientific animation plus explanation and screen text irrationality, the irrationality in increases the load of visual channel, affected the visual image on the image processing; Regardless of the interpretation of the cognitive theory, common sense and can feel: when you watch the pictures plus explanation and the text screen shows and teaching video, you may feel you are not 
looking at the picture, but looking at the screen text. So for those of pure video or multimedia courseware teaching video, in the case of a commentary, not advocating with subtitles.

The consistency principle The consistency principle refers to the consistency, and the teaching it demands in the multimedia courseware to eliminate irrelevant text, images, and sounds; Multimedia learning cognitive theory think irrelevant information will compete for the cognitive resources in working memory, the learners' attention to important information, interference of information processing. Have an error in the multimedia courseware is excessive pursuit of web design aesthetic feeling, thought design more beautiful multimedia courseware more reflect the quality of the courseware, which violates the principle of consistency and teaching design, the design of multimedia courseware is very beautiful, learners may be immersed in the art of beauty and busy teaching information; More importantly, the structure of knowledge and information in the multimedia courseware should keep consistency with the learner's cognitive processing, that is the design of multimedia courseware should can promote the learners' cognitive, is helpful for learners to information processing.

\section{Multimedia courseware of multimedia teaching innovation thinking}

What kind of multimedia courseware can effectively improve the teaching quality, this is a complicated problem, is also a problem that has seen and heard as well as. At present the production of multimedia courseware has the following four types.First, don't have any new idea, the teaching material content replication, or "clone".Second, better for refining and summarizing the teaching material content, increasing the per unit time class capacity and density, but its performance means too stiff. That is to say, no good use of multimedia software of a variety of effects to appropriately to display the content of the performance.Third, skillfully use all kinds of technique of expression of the multimedia software, video, audio, video, animation, etc are obtained using, good interface, has the very high level of art, and has the advantages of good fault tolerance and interactivity. But due to the grasp of the teaching material content is allowed to have not been able to show the teaching material content, well even empty, theme, level is not clear.Fourth, not only a good grasp of the teaching material content, and the proper use of multimedia software in various excellent technique of expression, to tell the contents of the gives a new expression. That is to say again in textbooks on the basis of the original creation, made his teaching courseware must be creative.

A good multimedia teaching courseware should be able to fully express good innovative textbook content and rich. Although the meaning of "innovative" itself is vague, can not be quantified standard, but according to innovative, multimedia courseware should be the contents of the original teaching materials to create, not only can make the students learned to leave deep impression, can stimulate students' creative thinking. Generally speaking, the rich creative elements of multimedia courseware should have the following several aspects.

Rich "personalized" display effect. Personalized here refers to every courseware should have their own style, even though the same teacher to make the same different contents of teaching material, also want to have different style, so that the different content can a memorable impression in the students' learning, and thus stimulate students rich and colorful imagination. In fact, that the courseware can rich personalized, is also the inspection teachers teaching ability to one of the symbols of high and low. Now most of the courseware can give a person a kind of bland, the feeling of monotony, the key is because of making courseware people don't really get rid of the traditional patterns of the teaching material is stuck in handwriting oral teaching atmosphere.

Interest expression and art form. The making of multimedia courseware in teaching and film and television works, although can't rich artistic creativity, but also should have the same effect. Courseware manufacture process, therefore, should also is a creative process of art, using the best form of expression, and built the affection set condition and set up the suspense, art is about the content of the image to concrete, vivid, make shows content can produce a strong artistic appeal. Specifically, an excellent multimedia courseware is a teacher's attentively, rather than using equipment "manufacturing".

Able to inspire the infinite imagination and creative thinking of students. The traditional 
teaching mode in our country, it is generally believed that rigid, mechanical, how many years in, give a person the sense with boring, make students form the habit of passive learning, it is a lack of enlightening and difficult to cultivate students' innovative thinking and ability of teaching mode. The current quality education in schools, the purpose is to overcome the shortcomings of traditional teaching. Quality-oriented education is to increase and strengthen the auxiliary teaching not only, more important is that through creative teaching method, stimulates the student to the boundless imagination and creative thinking, focus on cultivating the students' ability of innovation. Strictly speaking, the use of multimedia courseware for teaching, must be able to achieve the goal of this. If the making of courseware and traditional teaching mode, that is actually lost the significance of the use of modern teaching equipment. Therefore, the teacher in making multimedia courseware, the first is to pass what kind of art form, which should be considered to show the contents of the textbook, appropriately can so as to attract students' attention, become boring for pleasure, and through the ingenious artistic means, break through the teaching time and space limitations, to expand their horizons, so that the students can place oneself in the scene the atmosphere of classroom teaching, so as to stimulate students imagination and creative thinking. Pretty pass, is a creative multimedia courseware.

\section{Conclusion}

Multimedia courseware is to use the multimedia to show the teaching content and teaching environment, and multimedia learning cognitive theory explains the human from the learning mechanism of learning process of multimedia material, multimedia courseware in the use of multimedia learning theory to guide the multimedia design, the design for information processing, and promote meaningful learning in multimedia courseware has great significance.

\section{References}

[1] Liu explore multimedia teaching [J] Theory and Practice of Education, 2006, (08):. p36-37.

[2] Xu Bian Jun advantages of multi-Si body of teaching and status of the horse countermeasures [J] China Science and Technology Information .2006, (01):. p97-100.

[3] Fang Wei, Deng Desheng comparative study of multimedia teaching and traditional teaching methods [J] economist .2004, (005):.. p107-107.

[4] Dong, over Wen $\mathrm{Yu}$ multimedia teaching and traditional teaching pros in the analysis of vocational teaching [J] optical disc technology, 2008 (010):... p60-61.

[5] Well just music, road Fang, Rong improve dry love to explore the effect of multimedia teaching [J] Harbin College, 2004, (04):... p107-109.

[6]Apperson J, Laws E. Scepansky J. The impact of presentation graphics on students' experience $\mathrm{n}$ the cIassroom[J]. Computers \& Education, 2006,47(1): p116-126.

[7] Apperson J, Laws E, Scepansky J. An assessment of student preferences for PowerPoint presentation structure in undergraduate courses[J], Computers \& Education, 2008,50(1):1p48-153.

[8]Sun P, Cheng H. The design of instructional multimedia in e-Learning: A Media Richness

Theory-based approach[J]. Computers \& Education, 2007,49(3): p662-676.

[9]Craig R. Amernic J. PowerPoint presentation technology and the dynamics of teaching[J]. Innovative Higher Education, 2006,31(3): p147-160.

[10]Bartlett R, Strough J. Multimedia versus traditional course instruction in introductory social psychology [J]. Teaching of Psychology, 2003,30(4): p335-338. 